\title{
INSIDE Project: Individual Air Pollution Exposure, Extracellular Vesicles Signaling and Hypertensive Disorder Development in Pregnancy
}

Luca Ferrari $^{1}{ }^{1}$, Francesca Borghi ${ }^{2} \oplus$, Simona Iodice ${ }^{1}$, Dolores Catelan ${ }^{3}$, Stefano Rossi ${ }^{4}{ }^{\oplus}$, Ilaria Giusti ${ }^{5}$, Laura Grisotto ${ }^{3}$, Sabrina Rovelli ${ }^{2} \mathbb{C}$, Andrea Spinazzè ${ }^{2}{ }^{\circ}$, Rossella Alinovi ${ }^{4}$, Silvana Pinelli ${ }^{4}$, Laura Cantone ${ }^{1}$, Laura Dioni ${ }^{1}$, Benedetta Ischia ${ }^{6}$, Irene Rota ${ }^{7}$,

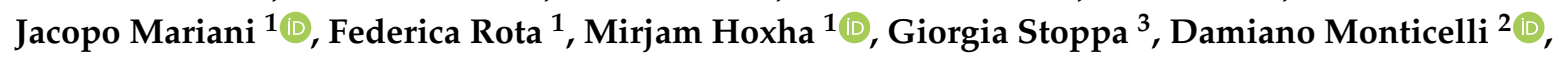
Domenico Cavallo ${ }^{2}$, Enrico Bergamaschi ${ }^{4,8}$, Marco Vicenzi ${ }^{7,9}$, Nicola Persico ${ }^{6,10}$, Annibale Biggeri ${ }^{3,+}\left(\mathbb{D}\right.$, Andrea Cattaneo ${ }^{2,+}\left(\mathbb{D}\right.$, Vincenza Dolo ${ }^{5,+} \oplus$, Michele Miragoli ${ }^{4,+}$, Paola Mozzoni ${ }^{4,+}+$ and Valentina Bollati ${ }^{1, *}$ (i)

1 EPIGET LAB, Department of Clinical Sciences and Community Health, Università degli Studi di Milano, 20122 Milan, Italy; luca.ferrari@unimi.it (L.F.); simona.iodice@unimi.it (S.I.); laura.cantone@unimi.it (L.C.); laura.dioni@unimi.it (L.D.); jacopo.mariani@unimi.it (J.M.); federica.rota@unimi.it (F.R.); mirjam.hoxha@unimi.it (M.H.)

2 Department of Science and High Technology, Università degli Studi dell'Insubria, 22100 Como, Italy; f.borghi2@uninsubria.it (F.B.); sabrina.rovelli@uninsubria.it (S.R.); andrea.spinazze@uninsubria.it (A.S.); damiano.monticelli@uninsubria.it (D.M.); domenico.cavallo@uninsubria.it (D.C.); andrea.cattaneo@uninsubria.it (A.C.)

3 Department of Statistics, Computer Science and Applications "G. Parenti", Università degli Studi di Firenze, 50134 Florence, Italy; dolores.catelan@unifi.it (D.C.); laura.grisotto@unifi.it (L.G.); giorgia.stoppa@unifi.it (G.S.); annibale.biggeri@unifi.it (A.B.)

4 Center of Excellence for Toxicological Research, Department of Medicine and Surgery, Università degli Studi di Parma, 43121 Parma, Italy; stefano.rossi@unipr.it (S.R.); rossella.alinovi@unipr.it (R.A.); silvana.pinelli@unipr.it (S.P.); enrico.bergamaschi@unito.it (E.B.); michele.miragoli@unipr.it (M.M.); paola.mozzoni@unipr.it (P.M.)

5 Department of Life, Health and Environmental Sciences, Università degli Studi dell'Aquila, 67100 L'Aquila, Italy; ilaria.giusti@univaq.it (I.G.); vincenza.dolo@univaq.it (V.D.)

6 Department of Obstetrics and Gynecology 'L. Mangiagalli', Fondazione IRCCS Ca' Granda Ospedale Maggiore Policlinico, 20122 Milan, Italy; benedetta.ischia@policlinico.mi.it (B.I.); nicola.persico@unimi.it (N.P.)

7 Cardiovascular Disease Unit, Department of Internal Medicine, Fondazione IRCCS Ca' Granda Ospedale Maggiore Policlinico, 20122 Milan, Italy; irene.rota@policlinico.mi.it (I.R.); marco.vicenzi@unimi.it (M.V.)

8 Department of Public Health Sciences and Pediatrics, Università di Torino, 10126 Turin, Italy

9 Dyspnea Lab, Department of Clinical Sciences and Community Health, Università degli Studi di Milano, 20122 Milan, Italy

10 Department of Clinical Sciences and Community Health, Università degli Studi di Milano, 20122 Milan, Italy

* Correspondence: valentina.bollati@unimi.it; Tel.: +39-02-503-20127

+ These authors contribute equally to this work.

Received: 9 October 2020; Accepted: 29 November 2020; Published: 4 December 2020

\begin{abstract}
Hypertensive disorders are common complications during pregnancy (HDP) with substantial public health impact. Acute and chronic particulate matter (PM) exposure during pregnancy increases the risk of HDP, although the underlying molecular mechanisms remain unclear. Extracellular vesicles (EVs) may be the ideal candidates for mediating the effects of PM exposure in pregnancy as they are released in response to environmental stimuli. The INSIDE project aims to investigate this mechanism in pregnancy outcomes. The study population is enrolled at the Fetal Medicine Unit of Fondazione IRCCS Ca'Granda-Ospedale Maggiore Policlinico at 10-14 weeks of gestation. Exposure to $\mathrm{PM}_{10}$ and $\mathrm{PM}_{2.5}$ is assessed using the flexible air quality regional model
\end{abstract}


(FARM) and Bayesian geostatistical models. Each woman provides a blood sample for EV analysis and circulating biomarker assessment. Moreover, a subgroup of recruited women $(n=85)$ is asked to participate in a cardiovascular screening program including a standard clinical evaluation, a non-invasive assessment of right ventricular function, and pulmonary circulation at rest and during exercise. These subjects are also asked to wear a personal particulate sampler, to measure $\mathrm{PM}_{10}$, $\mathrm{PM}_{2.5}$, and $\mathrm{PM}_{1}$. The INSIDE study is expected to identify the health impacts of PM exposure on pregnancy outcomes.

Keywords: air pollution exposure; hypertensive disorder development; pregnancy; extracellular vesicles

\section{Introduction}

Hypertensive disorders of pregnancy (HDP, including gestational hypertension, pre-eclampsia, and eclampsia) are common complications, affecting $2-10 \%$ of pregnancies, leading to a substantial public health impact [1,2]. Gestational hypertension is defined as a systolic blood pressure (SBP) of $\geq 140 \mathrm{mmHg}$ or diastolic blood pressure (DBP) of $\geq 90 \mathrm{mmHg}$ measured after 20 weeks of pregnancy in previously normotensive women [3]. Pre-eclampsia is characterized by hypertension in association with proteinuria/albuminuria [2]. In addition to non-negligible maternal mortality, pre-eclampsia and related conditions are a leading cause of maternal morbidity, perinatal death, and placental abruption [1].

Many health studies have demonstrated that exposure to acute [4-8] and chronic [9-12] particulate matter (PM) is associated with early death, particularly from cardiovascular (CV) disease $[5,11,13]$. There is also growing evidence that PM exposure during pregnancy is associated with an increased risk of developing HDP [14,15], due to an exaggerated systemic inflammatory response involving the CV system [16] and endothelium [2,17,18]. The causes of HDP are unclear, as are the molecular mechanisms linking PM exposure and HDP development.

At a functional level, the pulmonary vasoconstrictor effect of PM, combined with its systemic effects, might contribute towards explaining the link between exposure and a general decline in vascular distensibility [17]. Air pollution causes peripheral vascular dysfunction through endothelial vasoconstriction mediated by a reduction in nitric oxide (NO) activity and increased activation of endothelin-1 (ET-1) $[18,19]$. In the same way, air pollution causes pulmonary vasoconstriction, increasing pulmonary arterial pressure at rest, and during exercise [17].

Inhaled ultrafine PM might directly reach the systemic circulation from the pulmonary capillary bed, thus promoting atherothrombosis by stimulating a local inflammatory reaction and disrupting endothelial integrity $[13,20]$. Nonetheless, just a very slight portion of fine and ultrafine particles gathers in extrapulmonary structures [21]. Thus, evidence that fine particles actually enter and are deposited in blood vessels is lacking. Instead, the crosstalk between the lung and CV system might occur, potentially causing the observed peripheral effects of PM exposure [22,23].

Studies on the relationship between PM and health effects have generated a panel of circulating biomarkers reflecting inflammation [24], endothelial activation [25], platelet activation [26], oxidative damage to DNA and lipids, and antioxidant capacity $[27,28]$. Endothelial dysfunction occurs when a healthy endothelium becomes a damaged pro-coagulative, pro-inflammatory, and pro-vasoconstrictive phenotype. This event occurs early in many chronic diseases and reflects an imbalance in vascular function. During pregnancy, it is considered a key element in the development of pre-eclampsia [29].

Recent evidence produced by our research group showed that PM is able to modify the signaling of extracellular vesicles (EVs) [30-32]. This phenomenon represents a powerful mode of intercellular communication $[33,34]$. EVs are limited by a lipid bilayer and can be generated by cells, secreted into the extracellular space, and then enter biological fluids. EV membranes express adhesion molecules on their surface, favoring their capture by recipient cells. The fate of EVs after binding to the surface 
of recipient cells is not known. However, recent evidence indicates that EVs fuse with recipient cell membranes and deliver their content (e.g., miRNAs) directly to the cytoplasm of recipient cells, facilitating intercellular and inter-organ communication [35].

These characteristics of EVs make them ideal candidates for mediating the effects of PM exposure on pregnancy. For instance, EVs might be produced by the epithelial cells of the respiratory system, then translocate to the systemic circulation [36] where they interact with remote tissues, such as the placenta and maternal endothelium. Once here, they potentially deliver their cargo of bioactive molecules derived from the tissue of origin to target tissues, and post-transcriptionally regulate gene expression in recipient cells.

Furthermore, EVs might have a central role during pregnancy. Specifically, increasing quantities of syncytiotrophoblast-derived micro- and nanovesicles [37-39] are released during pathological pregnancy [38]. These EVs are shed from the syncytial epithelium (STB) of the placenta and are received by monocytes. This process stimulates the production of proinflammatory cytokines [40,41], perturbing maternal vascular endothelium. Endothelial damage precedes the overt manifestation of the disease and is associated with hypertension. In addition, elevated levels of soluble intercellular adhesion molecule-1 (sICAM-1) and circulating vascular cell adhesion molecule-1 (sVCAM-1) have been positively associated with preterm delivery independent of usual risk factors [42].

\section{Aims and Hypothesis}

The INSIDE study aims to assess the molecular effects of environmental PM exposure during pregnancy. The specific aims of this first funded INSIDE grant (PRIN 0152T74ZL_004) are summarized in Figure 1. The current study population includes 528 pregnant women (final target, $n=1000$ ) attending the Fetal Medicine Unit (FMU) of Fondazione IRCCS Ca'Granda-Ospedale Maggiore Policlinico for routine screening for fetal chromosomal and structural abnormalities at 10-14 weeks of gestation. A subgroup of recruited women $(n=85)$ was asked to participate in a CV screening program, including a standard clinical evaluation (Electrocardiogram, EKG, arterial pressure measurement, evaluation of known CV risk factors) and a non-invasive assessment. The non-invasive assessment includes evaluating how right and left ventricular function and pulmonary circulation adjust during rest versus exercise.

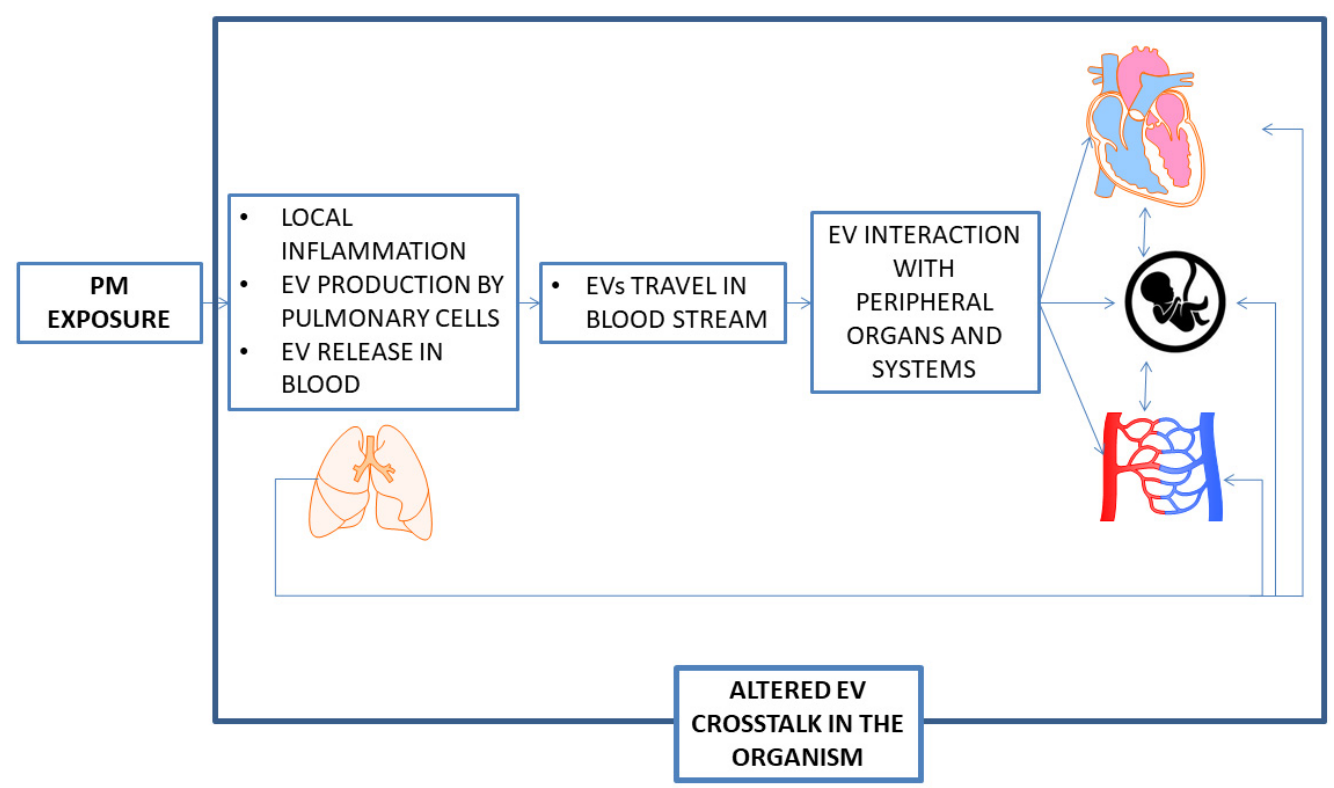

Figure 1. Rationale of the INSIDE project. PM: Particulate Matter; EV: Extracellular Vesicles.

The study is investigating whether (Figure 2): (1) exposure to PM modifies EVs in plasma, using the quantity, size, membrane surface marker expression, and miRNA content as measures; (2) EVs are 
associated with the development of HDP; (3) EVs are associated with parameters collected during CV screening; (4) EVs are associated with circulating biomarkers reflecting endothelial inflammation, increased coagulation, and vascular tone, and whether these parameters could be used as indicators of subclinical effects or to predict clinical outcomes involving endothelium homeostasis; (5) EVs are associated with adverse birth outcomes, such as low birth weight, preterm birth, and perinatal morbidity. The current manuscript presents the study design, field activities, management approach, and characteristics of the enrolled women.

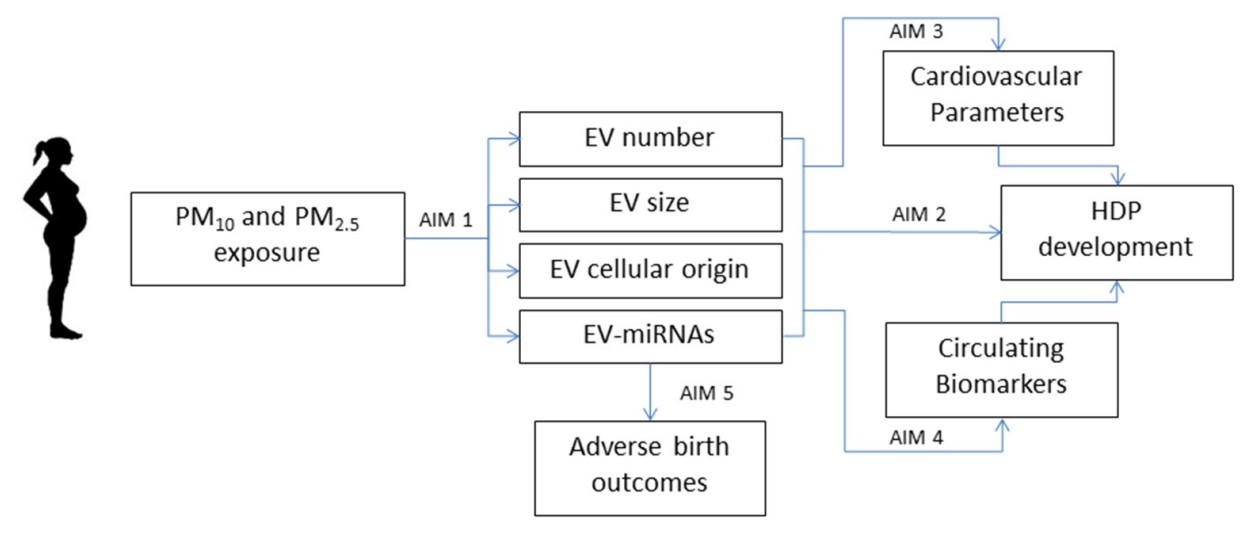

Figure 2. Specific aims of the INSIDE project. HDP: Hypertensive Disorders in Pegrnancy.

\section{Methods and Analysis}

\subsection{Study Design and Cohort Description}

The INSIDE study is a cross-sectional study that investigates how exposure to air pollution impacts a population of pregnant women residing in the Lombardy region, Italy. The "Clinica Mangiagalli", Fondazione IRCCS Ca'Granda-Ospedale Maggiore Policlinico is a hospital located in Milan, Italy, which is the capital city of the Lombardy region. The "Clinica Mangiagalli" has the highest number of births in Lombardy.

The target of the INSIDE study is the enrolment of 1000 women attending the FMU for screening for fetal chromosomal and structural abnormalities at 10-14 weeks of gestation. The recruitment period started in June 2014 and is ongoing. So far, 518 subjects have been enrolled. We are currently seeking further funding to complete the accrual of 1000 subjects. The eligibility criteria for participants were: (1) older than 18 years at enrolment; (2) physiological pregnancy; (3) resident in Lombardy at the time of recruitment; and (4) agreed to sign an informed consent and donate a blood sample. Exclusion criteria included a previous diagnosis of cancer and cardiovascular diseases or other chronic diseases, such as multiple sclerosis, epilepsy, schizophrenia, and depression. The participation rate of the overall population was $76 \%$. The main characteristics of the study participants are reported in Table 1. The mean age is $33.8( \pm 4.3)$ years and the mean gestational age at enrolment is $11.9( \pm 0.7)$ weeks. It was the first pregnancy for $60.8 \%$ of the women, with the remainder having had one or more children. The mean pre-pregnancy body mass index (BMI) is $22.4( \pm 3.7) \mathrm{kg} / \mathrm{m}^{2}$.

Table 1. Characteristics of study participants.

\begin{tabular}{lc}
\hline \multicolumn{1}{c}{ Characteristic $(\mathbf{n}=\mathbf{5 1 8})$} & Value \\
\hline Age, mean \pm SD, year & $33.8 \pm 4.3$ \\
Gestational age at sample, weeks & $11.9 \pm 0.7$ \\
\hline Season of Enrollment, $\mathbf{n}(\mathbf{\%})$ & \\
Winter & $161 \pm 31.1$ \\
Spring & $116 \pm 22.4$ \\
\hline
\end{tabular}


Table 1. Cont.

\begin{tabular}{|c|c|}
\hline Characteristic $(n=518)$ & Value \\
\hline Summer & $100 \pm 19.3$ \\
\hline Autumn & $141 \pm 27.2$ \\
\hline Anthropometric and Biochemical Features & \\
\hline$\overline{\mathrm{BMI}, \mathrm{Kg} / \mathrm{m}^{2}}$ & $22.4 \pm 3.7$ \\
\hline $\begin{array}{l}\text { Categorical BMI } \\
\text { Underweight }(\mathrm{BMI}<18.5) \\
\text { Lean }(18.5 \leq \mathrm{BMI}<25) \\
\text { Overweight }(\mathrm{BMI} \geq 25) \\
\text { Glucose, } \mathrm{mg} / \mathrm{dL} \\
\text { Total Cholesterol }(\mathrm{TC},) \mathrm{mg} / \mathrm{dL} \\
\text { Low-density lipoprotein-Cholesterol (LDL-C), mg/dL } \\
\text { Lipoprotein a, mg/dL } \\
\text { non-High Density Lipoprotein-Cholesterol HDL-C, mg/dL } \\
\text { HDL-C, mg/dL } \\
\text { Triglycerides (TG), mg/dL } \\
\text { Proprotein convertase subtilisin/kexin type } 9 \text { (PCSK9), ng/mL } \\
\text { Intracellula Adhesion Molecul (ICAM), pg/mL } \\
\text { Vascular cell adhesion protein }(\mathrm{VCAM}), \mathrm{pg} / \mathrm{mL} \\
\text { C-reactive Protein }(\mathrm{CRP}) \mathrm{mg} / \mathrm{dL} \\
\text { Fibrinogen, mg/dL } \\
\text { IL-6, pg/mL } \\
\text { Serpin, pg/ml }\end{array}$ & $\begin{array}{c}50(9.8 \%) \\
358(69.8 \%) \\
105(20.5 \%) \\
86.5 \pm 14.6 \\
181.9 \pm 29.2 \\
97.4 \pm 22.1 \\
6(3,13) \\
116.8 \pm 25.0 \\
65.5 \pm 13.9 \\
91.6(69.6,112.6) \\
182.6(155.2,224.7) \\
339,664 \pm 67,973 \\
786,866 \pm 179,405 \\
2.6(1.5,4.6) \\
139.3(112.2,174.6) \\
1.7(1.4,2.1) \\
19,098(13825,25089)\end{array}$ \\
\hline Smoking Habits, n (\%) & \\
\hline $\begin{array}{l}\overline{\text { Never smoked }} \\
\text { Stopped during pregnancy } \\
\text { Smoker }\end{array}$ & $\begin{array}{c}435(84.0 \%) \\
55(10.6 \%) \\
25(4.8 \%)\end{array}$ \\
\hline Features Related to Pregnancy & \\
\hline $\begin{array}{l}\text { Parity } \\
\text { Nulliparity } \\
\text { Multiparity }\end{array}$ & $\begin{array}{l}315(60.8 \%) \\
201(38.8 \%)\end{array}$ \\
\hline $\begin{array}{l}\text { Pregnancy-associated endocrine factors } \\
\text { Pregnancy-associated plasma Protein A (PAPPA), IU/L, median (Q1, Q3) } \\
\text { Placental Growth Factor PLGF, pg/mL } \\
\text { Human chorionic gonadotropic hCG, IU/L } \\
\text { PAPPA Multiple of the Median (MoM) } \\
\text { hCG MoM } \\
\text { PLGF MoM }\end{array}$ & $\begin{array}{l}2.8(1.8-4.0) \\
30.6(24.0-37.8) \\
46.3(30.2-70.2) \\
1.2(0.8,1.7) \\
1.0(0.7,1.6) \\
1.1(0.9,1.4)\end{array}$ \\
\hline $\begin{array}{l}\text { Birth delivery mode, } n(\%) \\
\text { Spontaneous } \\
\text { Induction } \\
\text { Cesarean } \\
\text { Gestational age at birth }\end{array}$ & $\begin{array}{c}362(69.9 .0 \%) \\
86(16.6 .5 .0 \%) \\
68(13.1 \%) \\
39.3 \pm 2.2\end{array}$ \\
\hline $\begin{array}{l}\text { Fetal Parameters } \\
\text { Crown-rump length } \\
\text { Nuchal translucency thickness } \\
\text { Fetal heart rate } \\
\text { Ductus venosus pulsatility index } \\
\text { Mean blood pressure, mmHg } \\
\text { Mean uterine artery pulsatility index }\end{array}$ & $\begin{array}{l}62.8 \pm 6.4 \\
1.9 \pm 0.5 \\
160.3 \pm 7.3 \\
1.0 \pm 0.2 \\
85.8 \pm 7.5 \\
1.6 \pm 0.4\end{array}$ \\
\hline $\begin{array}{l}\text { Neonatal Parameters } \\
\text { Weight }(\mathrm{g}) \\
\text { Length }(\mathrm{cm}) \\
\text { Cranial circumference }(\mathrm{cm}) \\
\text { Apgar score }\end{array}$ & $\begin{array}{c}3248.9 \pm 451 \\
49.9 \pm 2 \\
34.2 \pm 1.5 \\
9.8 \pm 0.6\end{array}$ \\
\hline
\end{tabular}




\subsection{Epidemiological and Clinical Data Collection}

Pre-gestational maternal information (such as age, educational level, ethnicity, parity, and folic acid supplementation) are obtained using a questionnaire at enrollment. Information on place of residence, cigarette smoking, alcohol consumption, medical history, and medication are also collected. For the specific purpose of the present project, each patient is asked to: (1) sign an informed consent form explaining the study aims and procedures; and (2) provide a $15 \mathrm{~mL}$ peripheral blood sample. We also asked 85 enrolled patients to undergo a cardiac ultrasound and to be available for being recalled during the second (20-24 weeks) trimester of the gestational period for a cardiovascular follow-up. Repeated measurements analysis was performed at rest and after exercise to explore patterns in the cardiovascular response.

\subsection{Cardiovascular Assessment}

The clinical assessment of patients includes at rest evaluation through blood pressure, heart rate, and peripheral arterial oxygen saturation $\left(\mathrm{SpO}_{2}\right)$. Flow-mediated dilation of the brachial artery is performed by adopting a standard approach. In brief, vessel diameter and blood flow at rest are compared with those measured $5 \mathrm{~min}$ after distal occlusion. We record endothelial response every $15 \mathrm{~s}$ over a $90 \mathrm{~s}$ period after the release of occlusion.

$\mathrm{CV}$ adaptation during effort is assessed through a cardiorespiratory exercise test (CPET) that is combined with exercise echocardiography on a semi-recumbent cycle ergometer tilted $20^{\circ}$ to $30^{\circ}$ to the left. Once a warm-up phase at 15 Watts ends, standardized effort with stages of 20 Watts every $2 \mathrm{~min}$ starts. Based on the international guidelines for the exercise test, continuous monitoring of cardiac rhythm and blood pressure is carried out during effort. Exercise is stopped when $70 \%$ of maximal heart rate is achieved (formula: 220-age of the subject). Cardiac output (Q), mean pulmonary arterial pressure (mPAP), and left atrial filling pressure (LAP) are calculated from echocardiography-derived equations. Total pulmonary vascular resistance is calculated as the $\mathrm{mPAP} / \mathrm{Q}$ ratio. Pulmonary vascular adaptation to exercise is described by the slope of the multipoint mPAP-Q curve. The CPET is used to qualify the respiratory response and quantify the rise in ventilation per minute induced by exercise.

\subsection{Measures of the Fetus}

Measurements of the fetus are collected as part of the prenatal screening test, during which the fetus is examined by ultrasound and blood is drawn for the INSIDE project. During ultrasound examination, data about crown-rump length, nuchal translucency, and fetal heart rate are registered. Gestational age is calculated from the first day of the last menstrual period.

\subsection{Outcome at Birth}

Information on the evolution of fetal growth and neonatal conditions is obtained from the Certificate of Delivery Care (registry from Lombardy Region). Neonatal weight $(\mathrm{g})$, neonatal length $(\mathrm{cm})$, cranial circumference $(\mathrm{cm})$, and Apgar score are registered.

\subsection{Collection of Biological Samples}

We developed a specific standard operating procedure to guarantee the quality control of each step involved in sample collection and analysis. Blood is collected in ethylenediaminetetraacetic acid (EDTA) tubes $(7 \mathrm{~mL})$, and transported to the EPIGET Lab (University of Milan) within $2 \mathrm{~h}$ of phlebotomy. Blood-EDTA is processed to separate buffy coat and plasma, by centrifuging at $1100 \times g$ for $15 \mathrm{~min}$ at room temperature. To obtain the EV pellet, an aliquot of plasma is further centrifuged at 1000, 2000, and $3000 \times g$ for $15 \mathrm{~min}$ at $4{ }^{\circ} \mathrm{C}$ to remove cell debris. It is then transferred to an ultracentrifuge tube (Quick-Seal-Round-Top, polypropylene, $13.5 \mathrm{~mL}$, Beckman Coulter, Inc., Brea, CA, USA), and diluted with phosphate-buffered saline (PBS). 


\subsection{Investigation of Extracellular Vesicles}

EVs are investigated by characterizing the determinants of several membrane determinants that are suggestive of EV cellular origin. EV size, EV count by nanoparticle tracking analysis (Nanosight NS300, Malvern Panalytical, Malvern, UK), and EV content (in particular, microRNAs) are also analyzed. For miRNA analysis, we follow a two-stage, split-sample study design. The discovery stage was conducted on the first 212 women consecutively recruited by OpenArray technology QuantStudio ${ }^{\mathrm{TM}} 12 \mathrm{~K}$ Flex (Thermofisher Scientific, Waltham, MA, USA), which is a fixed-content panel containing validated human TaqMan microRNA assays derived from Sanger miRBase release v.14 [43]. The panel analysis screens 754 miRNAs and the full list of targets investigated is available online [44]. The validation stage is being conducted by standard real-time PCR on the top differential miRNAs defined at the discovery stage.

\subsection{Biochemical Measurements}

Circulating biomarkers reflecting inflammation status (IL-6), coagulation activation, and early systemic prothrombotic effects (C-reactive protein, plasma fibrinogen, plasminogen activator inhibitor-1) are evaluated, along with the functional assessment of the endothelium (circulating levels of inflammatory mediators, sICAM-1 and sVCAM-1), in human plasma samples using quantitative sandwich enzyme immunoassay techniques. Assays are performed using the Ella Automated Immunoassay System (ProteinSimple, San Jose, CA, USA) inside a patented glass nano-reactor. The entire process is controlled with microfluidics.

\subsection{Exposure Assessment}

\subsubsection{FARM Model}

Daily concentrations of air pollutants $\left(\mathrm{PM}_{10}\right.$ and $\left.\mathrm{PM}_{2.5}\right)$ are derived from the archives of the Regional Environmental Protection Agency (ARPA Lombardy). This organization collects data at a regional scale using the flexible air quality regional model (FARM) chemical-physical model of air quality [45]. This model is a three-dimensional Eulerian model that simulates the dispersion and chemical reactions of atmospheric pollutants. The system for forecasting pollutant concentrations is composed of a meteorological model powered by simulation data. In comparison, for the initial and boundary conditions, the outputs of the "Quale Aria" system are used [46]. Emissions are retrieved from regional, national, and European inventories. The domain of the simulation with the air quality FARM covers the entire Lombardy region with a grid of $1 \times 1 \mathrm{~cm}^{2}$ cells generated by the website, with daily estimates at municipality resolution (Figure 3). Finally, concentration data measured from the stations of the ARPA air quality network are integrated in the simulation results using interpolation techniques [47]. The estimated levels of daily $\mathrm{PM}_{10}$ and $\mathrm{PM}_{2.5}$ are assigned to each subject for the day of evaluation and 90 days before blood is sampled. We also calculate the average exposure from the day of the clinic visit and 90 days earlier. All participants are assigned pollutant levels that are estimated in the place of residence and in the municipality of Milan. 

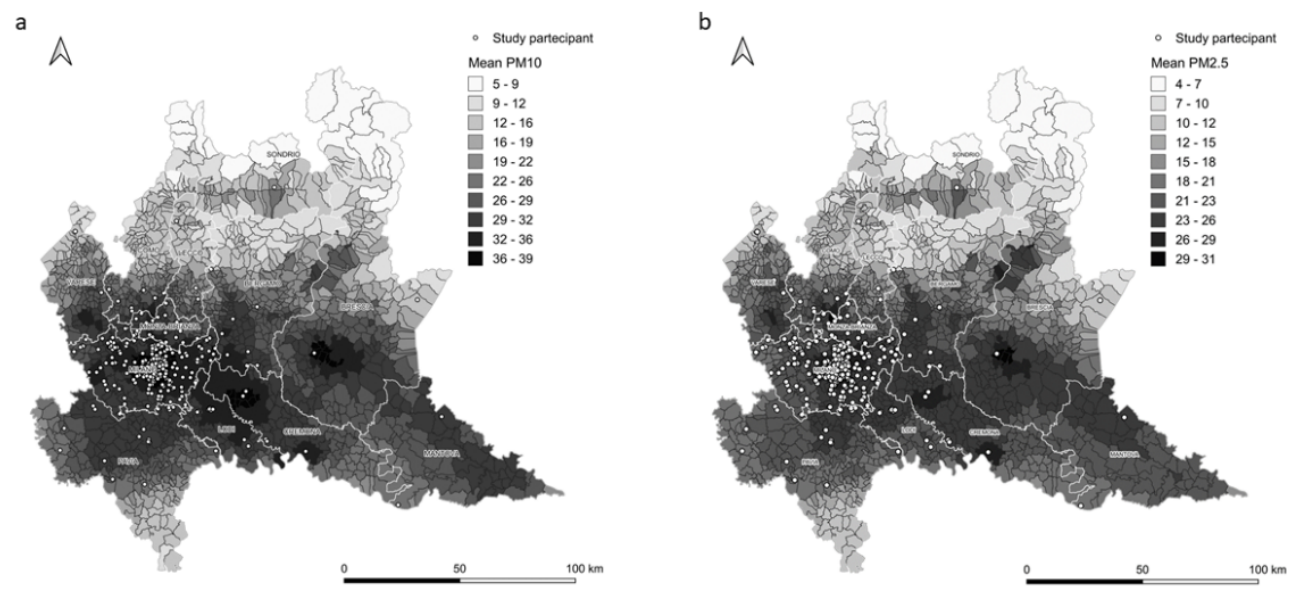

Figure 3. $\mathrm{PM}_{10}$ (2014-2019; (a)) and $\mathrm{PM}_{2.5}$ (2014-2019; (b)) concentration estimates at municipality resolution predicted by the flexible air quality regional model (FARM).

\subsubsection{Bayesian Geostatistical Model}

Using monitored data from the air quality network and the output of a photochemical deterministic model of the Environmental Protection Agency for the Lombardy region, we are currently developing a Bayesian geostatistical model to account for land use covariates, uncertainty in deterministic model outputs, and preferential sampling due to non-random monitoring locations [48-50].

\subsubsection{Personal Air Pollution Measurements}

Personal exposure to PM was measured in a subset of 85 pregnant women over two consecutive winter periods (October 2017-April 2018 and October 2018-April 2019). Subjects were instructed to wear a personal sampling device to measure exposure levels continuously over a $1-6 \mathrm{~h}$ period before clinical evaluation. During the monitoring period, all the enrolled subjects were requested to do their routine activities. Exposure to fractionated PM $\left(\mathrm{PM}_{1}, \mathrm{PM}_{2.5}, \mathrm{PM}_{4}, \mathrm{PM}_{10}\right.$, and TSP-Total suspended particles) was evaluated through a direct-reading monitor (Aerocet 831-Met One Instrument Inc., Grant Pass, OR, USA) set with an acquisition rate of $1 \mathrm{~min}$. To improve accuracy, a posteriori corrections were applied to raw data based on daily comparisons with gravimetric $\mathrm{PM}_{2.5}$ data collected by a Harvard impactor (Diagnostic and Engineering, Inc., Harrison, ME, USA), which was used as a gold standard [51]. A mobile phone (LG K4 2017) with an Android application (Geo tracker GPS tracker; Version 3.3.0) was used to determine and record subjects' position during the monitoring sessions. In order to make the reconstruction of the routes traveled and the visited environments more complete, the enrolled subjects were asked to fill a time activity diary.

\subsubsection{Sample Size}

The power calculation was based on testing the association of short-term exposure with the sum of EVs using standardized regression coefficients. A sample size of 1000 pregnant women was estimated to achieve $95 \%$ power to detect a reduction in the EV slope from a 0.10 standard deviation (SD) under the null hypothesis to a $0.16 \mathrm{SD}$ under the alternative hypothesis for a $1 \mathrm{SD}$ change in exposure. From our preliminary analysis, we assume a correlation between $\mathrm{PM}_{10}$ and the sum of EVs of 0.30 , and a two-sided significance level of 0.05 . The same approach was used to define the sample size for the subgroup of women enrolled for the personal sample exposure measure. The sample size was based on testing the association of short-term exposure on the rest heart rate (HR). A sample size of 85 pregnant women was estimated to achieves $90 \%$ power to detect a change in the rest HR slope from a 0.10 SD under the null hypothesis to a $0.99 \mathrm{SD}$ under the alternative hypothesis for a $1 \mathrm{SD}$ change in exposure. From our preliminary analysis, we assume a correlation between $\mathrm{PM}_{10}$ and the rest $\mathrm{HR}$ of 0.37 . 


\subsubsection{Statistical Analysis}

Descriptive statistics will be performed on all variables. Graphical inspection of the main variables of interest will be performed to examine their distribution and uncover the need for eventual transformation. Given the specific aims of the INSIDE project reported in Figure 2, we will evaluate the associations between individual and particulate matter exposure in the following outcomes: EV concentration and miRNAs, cardiovascular parameters, adverse birth outcomes, HDP parameters, and circulating biomarkers. As a second step, we will perform mediation analyses to estimate the extent to which the EV concentration and miRNAs mediate the effects of PM exposure on each specific outcome.

Multivariable modeling will be based on both biological and statistical considerations. For each outcome, we will identify a priori covariates that need to be controlled for, based on biological consideration and the current state of the literature. Other potential confounders will be included in the multivariate model after having verified the presence of an association in a univariate model. The best model selection will be based on the minimization of the Akaike information criterion and maximization of the explained variance of the model. We will conduct residual analysis to confirm model fit, identify highly influential data points, and possible nonlinear relationships between predictors and outcomes.

Finally, the best model will be selected to predict the association between PM exposure and each specific outcome.

To compare the magnitude of the association with different exposures, we will calculate standardized regression coefficients, which represent the change (standard deviation) in a dependent variable resulting from one standard deviation change in the independent variable.

Due to the high number of comparisons, we will apply a multiple comparison correction method based on the Benjamini-Hochberg false discovery rate (FDR) to calculate the FDR $p$-value.

Multivariable linear regression models will be also used to test the association between PM exposure and outcome in the mediation analysis framework, where we hypothesize that the relationship can be mediated through changes in miRNA expression, EV count, or their characterization. Each EV count and each miRNA will be separately considered as a potential mediator in a mediation model. We will estimate the direct effect and the indirect (mediated) effect with bias-corrected bootstrap confidence intervals.

All statistical analyses will be performed by using SAS 9.4 statistical software (SAS Institute Inc., Cary, NC, USA) and R software (version 3.6.1; Foundation for Statistical Computing, Vienna, Austria). Mediation analyses will be executed on the SAS v9.4 macro, using the PROCESS program provided by Bolin [52]

\section{Ethics and Dissemination}

The study design, research aims, and measurements were approved by the Ethics Committee "Comitato Etico-Milano Area 2" of the Fondazione IRCCS Ca' Granda Ospedale Maggiore Policlinico, 20122 Milan, Italy (approval number \#318), in accordance with principles of the Helsinki Declaration. Each participant signed a written informed consent form including a detailed description of the study. The measurements of new parameters will only be inserted in the study after the approval of the Ethical Committee. The datasets used and/or analyzed during the current study are available from the corresponding author on reasonable request.

All the scientific communications will be carried out under the responsibility of the study principal investigator with the agreement of the collaborators.

\section{Data Management and Privacy Protection}

The INSIDE study collects a large amount of information. To protect the privacy of each subject, all information and biological samples collected are anonymized of personal identifying information and can be identified only through a five-digit randomly assigned barcode. The link between the 
barcode and the subject's identity is held in a secure database. All the data collected through the questionnaire forms are imputed in the database, and quality and completeness controls are performed weekly. All data are combined in a central relational database (MS SQL Server). Data processing is anonymous, and the highest level of confidentiality is maintained for all identifying information. We check the quality of collected data by comparing information from different sources (e.g., clinical records, molecular and biochemical exams), assessing the ranges and distributions of variables, evaluating the quality of biospecimens through specific analyses conducted on random samples, and verifying database completeness through multiple queries. The complete list of all collected variables is provided in Supplementary Materials Table S1.

\section{Opportunities to Collaborate}

We designed INSIDE due to our awareness that its value would consistently increase thanks to the involvement of other investigators, as individuals, and within consortia. The INSIDE project is open for collaboration. Given the detailed epidemiological data available, such as the clinical information and molecular data collected, INSIDE offers a good opportunity to collaborate. Proposals to test specific hypotheses on the INSIDE population that come from outside the study team will be reviewed by our research team. Requests can be sent to the e-mail valentina.bollati@unimi.it.

\section{Discussion}

The investigation of mechanisms linking the inhalation of particulate air pollutants to negative health effects is considered a pressing priority $[53,54]$. In particular, it is important to acquire knowledge of how air pollutants impact hypersusceptible populations, including pregnant women, who are widely documented to have high sensitivity to several toxicants and pollutants, including fine particles. Moreover, adverse effects on the wellbeing of pregnant women and their newborn children are not acceptable, given their very high social and public health impact [1].

In fact, pre-eclampsia, and consequent fetal growth restriction and preterm births, are related to acute maternal and neonatal mortality and morbidity. It is also associated with long-term compliance and social costs. For instance, pre-eclampsia decreases the future health-related quality of life of mothers and increases the risk of post-partum depression [1-3]. Moreover, children born to mothers with pre-eclampsia have an increased short-term risk of bronchopulmonary and cerebral complications, as well as a long-term increased risk of hypertension, diabetes, and metabolic diseases $[13,55,56]$.

Large epidemiological studies have demonstrated adverse pregnancy outcomes associated with high levels of maternal PM exposure [57-60]. However, the molecular and biological mechanisms linking the inhalation of PM with fetal homeostasis are still lacking. Consequently, the involved mechanisms that could be potentially modified by preventive or drug-based interventions remain unknown and, hence, untreatable. However, the identification of miRNAs in the plasma of the EVs of healthy subjects potentially provides information on the potential mechanism that alters maternal blood pressure. Specifically, EVs produced by the lungs after PM stimulation might be able to transfer a specific pattern of miRNAs to other regions of the body, such as the placenta or endothelium $[32,35,36]$.

Our multi-step approach was specifically designed to elucidate how EVs contribute to the casual pathway from maternal exposure to pregnancy outcomes (based on tissue-specific processes and functions) and is expected to generate biologically meaningful results. This study is examining these mechanisms in a large group of pregnant women, who are being recruited from the biggest and most important maternal clinic of Milan. The metropolitan area of this Italian city is characterized by one of the highest levels of PM in Europe. EV production and content (miRNAs) in plasma are measured in the recruited women at critical time points. Plasma is an easily obtainable biological medium and can be safely obtained, even from pregnant women. If we were successful in identifying changes to miRNAs in EVs, this information might be useful in clinical settings to generate potential future preventive and diagnostic applications. In addition, the miRNAs in EVs might also be a drug target, 
potentially opening pathways to develop future interventions to reverse the effects of air pollution in pregnant women, generating positive public health impact.

Moreover, our investigation focused on identifying molecular and biological changes before the development of a critical disease that is difficult to mitigate (maternal hypertension, pre-eclampsia, and consequent preterm delivery). It is important to identify pre-clinical effects in environmental health studies because pre-clinical effects impact a large component of the exposed population when pollutant levels are moderately low, such as in urban areas outside periods of PM peaks. This information would also allow physicians to implement effective preventative measures. Finally, it is important to assess biochemical and functional abnormalities to determine casual pathways, ranging from exposure to disease, and to elucidate critical mechanisms to help mitigate effects in pregnant women and the general population.

\section{Conclusions}

The outputs of the INSIDE project are expected to identify the health impacts of PM exposure and to determine risks to the general population, particularly the hypersusceptible sub-population of pregnant women. This information is necessary to develop evidence-based preventive health care programs. In conclusion, our results are expected to contribute to the priorities of the National Prevention Plan, which considers pollution risk prevention as a key objective.

\section{Patient and Public Involvement}

Patients and/or the public were not involved in the design, or conduct, or reporting, or dissemination plans of this research.

Supplementary Materials: The following are available online at http://www.mdpi.com/1660-4601/17/23/9046/s1, Table S1: List of all collected variables.

Author Contributions: V.B. had full access to all the data in the study and takes responsibility for the integrity of the data and the accuracy of the data analysis; V.B., V.D., P.M., M.M., and E.B. designed and supervised the molecular study; A.B. designed and supervised the epidemiological implant of the study; A.C. and D.C. (Domenico Cavallo) coordinated personal exposure assessment; M.V., N.P., I.R., and B.I. coordinated patient recruitment and the database of clinical variables preparation; S.R. (Stefano Rossi), I.G., R.A., S.P., L.C., L.D., F.R., M.H., and J.M. undertook the lab procedures; L.F. supervised molecular lab activities; F.B., S.R. (Sabrina Rovelli), A.S., D.M., and A.C. performed collection, quantification, and characterization of airborne particles; S.I., L.G., G.S., D.C. (Dolores Catelan), and A.B. statistically analyzed the data; L.F. drafted the manuscript; V.B., A.C., P.M., V.D., A.B., and M.M. revised the manuscript; V.B., A.C., E.B., V.D., A.B., and M.M. obtained funding. All authors have read and agreed to the published version of the manuscript.

Funding: The study was funded by the governmental funding program of the Italian Ministry of Education, University, and Research "Progetti di Rilevante Interesse Nazionale" (PRIN) PRIN 0152T74ZL_004 to the INSIDE consortium (V.B., V.D., A.C., P.M., A.B.). The funder did not take part in the study design.

Acknowledgments: We thank the obstetrics and gynecology and cardiology residents for their help in examining and recruiting the study subjects. We are grateful to the nurses of the Fondazione IRCCS Ca' Granda Ospedale Maggiore Policlinico as well as the volunteers who participated in the study.

Conflicts of Interest: The authors declare no conflict of interest.

\section{References}

1. Mol, B.W.J.; Roberts, C.T.; Thangaratinam, S.; Magee, L.A.; de Groot, C.J.M.; Hofmeyr, G.J. Pre-eclampsia. Lancet 2016, 387, 999-1011. [CrossRef]

2. Steegers, E.A.P.; von Dadelszen, P.; Duvekot, J.J.; Pijnenborg, R. Pre-eclampsia. Lancet 2010, 376, 631-644. [CrossRef]

3. American College of Obstetricians and Gynecologists; Task Force on Hypertension in Pregnancy. Hypertension in pregnancy. Report of the American College of Obstetricians and Gynecologists' Task Force on Hypertension in Pregnancy. Obstet. Gynecol. 2013, 122, 1122-1131. [CrossRef]

4. Schwartz, J.; Marcus, A. Mortality and air pollution in London: A time series analysis. Am. J. Epidemiol. 1990, 131, 185-194. [CrossRef] 
5. Schwartz, J.; Dockery, D.W. Increased mortality in Philadelphia associated with daily air pollution concentrations. Am. Rev. Respir. Dis. 1992, 145, 600-604. [CrossRef] [PubMed]

6. Katsouyanni, K.; Touloumi, G.; Spix, C.; Schwartz, J.; Balducci, F.; Medina, S.; Rossi, G.; Wojtyniak, B.; Sunyer, J.; Bacharova, L.; et al. Short-term effects of ambient sulphur dioxide and particulate matter on mortality in 12 European cities: Results from time series data from the APHEA project. Air Pollution and Health: A European Approach. BMJ 1997, 314, 1658-1663. [CrossRef]

7. Katsouyanni, K.; Touloumi, G.; Samoli, E.; Gryparis, A.; Le Tertre, A.; Monopolis, Y.; Rossi, G.; Zmirou, D.; Ballester, F.; Boumghar, A.; et al. Confounding and effect modification in the short-term effects of ambient particles on total mortality: Results from 29 European cities within the APHEA2 project. Epidemiology 2001, 12, 521-531. [CrossRef]

8. Kinney, P.L.; Ozkaynak, H. Associations of daily mortality and air pollution in Los Angeles County. Environ. Res. 1991, 54, 99-120. [CrossRef]

9. Dockery, D.W.; Pope, C.A., 3rd; Xu, X.; Spengler, J.D.; Ware, J.H.; Fay, M.E.; Ferris, B.G., Jr.; Speizer, F.E. An association between air pollution and mortality in six U.S. cities. N. Engl. J. Med. 1993, 329, 1753-1759. [CrossRef]

10. Pope, C.A., 3rd; Thun, M.J.; Namboodiri, M.M.; Dockery, D.W.; Evans, J.S.; Speizer, F.E.; Heath, C.W., Jr. Particulate air pollution as a predictor of mortality in a prospective study of U.S. adults. Am. J. Respir. Crit. Care Med. 1995, 151, 669-674. [CrossRef]

11. Pope, C.A., 3rd; Burnett, R.T.; Thurston, G.D.; Thun, M.J.; Calle, E.E.; Krewski, D.; Godleski, J.J. Cardiovascular mortality and long-term exposure to particulate air pollution: Epidemiological evidence of general pathophysiological pathways of disease. Circulation 2004, 109, 71-77. [CrossRef] [PubMed]

12. Iodice, S.; Hoxha, M.; Ferrari, L.; Carbone, I.F.; Anceschi, C.; Miragoli, M.; Pesatori, A.C.; Persico, N.; Bollati, V. Particulate Air Pollution, Blood Mitochondrial DNA Copy Number, and Telomere Length in Mothers in the First Trimester of Pregnancy: Effects on Fetal Growth. Oxidat. Med. Cell Longev. 2018, 2018. [CrossRef] [PubMed]

13. Ferrari, L.; Carugno, M.; Bollati, V. Particulate matter exposure shapes DNA methylation through the lifespan. Clin. Epigenet. 2019, 11, 1-14. [CrossRef] [PubMed]

14. Pedersen, M.; Stayner, L.; Slama, R.; Sorensen, M.; Figueras, F.; Nieuwenhuijsen, M.J.; Raaschou-Nielsen, O.; Dadvand, P. Ambient air pollution and pregnancy-induced hypertensive disorders: A systematic review and meta-analysis. Hypertension 2014, 64, 494-500. [CrossRef] [PubMed]

15. Alemayehu, Y.A.; Asfaw, S.L.; Terfie, T.A. Exposure to urban particulate matter and its association with human health risks. Environ. Sci. Pollut. Res. Int. 2020, 27, 27491-27506. [CrossRef] [PubMed]

16. Yoder, S.R.; Thornburg, L.L.; Bisognano, J.D. Hypertension in pregnancy and women of childbearing age. Am. J. Med. 2009, 122, 890-895. [CrossRef] [PubMed]

17. Wauters, A.; Vicenzi, M.; De Becker, B.; Riga, J.P.; Esmaeilzadeh, F.; Faoro, V.; Vachiery, J.L.; van de Borne, P.; Argacha, J.F. At high cardiac output, diesel exhaust exposure increases pulmonary vascular resistance and decreases distensibility of pulmonary resistive vessels. Am. J. Physiol. Heart Circ. Physiol. 2015. [CrossRef]

18. Wauters, A.; Dreyfuss, C.; Pochet, S.; Hendrick, P.; Berkenboom, G.; van de Borne, P.; Argacha, J.F. Acute exposure to diesel exhaust impairs nitric oxide-mediated endothelial vasomotor function by increasing endothelial oxidative stress. Hypertension 2013, 62, 352-358. [CrossRef]

19. Calderon-Garciduenas, L.; Vincent, R.; Mora-Tiscareno, A.; Franco-Lira, M.; Henriquez-Roldan, C.; Barragan-Mejia, G.; Garrido-Garcia, L.; Camacho-Reyes, L.; Valencia-Salazar, G.; Paredes, R.; et al. Elevated plasma endothelin-1 and pulmonary arterial pressure in children exposed to air pollution. Environ. Health Perspect. 2007, 115, 1248-1253. [CrossRef]

20. Nemmar, A.; Vanbilloen, H.; Hoylaerts, M.F.; Hoet, P.H.; Verbruggen, A.; Nemery, B. Passage of intratracheally instilled ultrafine particles from the lung into the systemic circulation in hamster. Am. J. Respir. Crit. Care Med. 2001, 164, 1665-1668. [CrossRef]

21. Mills, N.L.; Amin, N.; Robinson, S.D.; Anand, A.; Davies, J.; Patel, D.; de la Fuente, J.M.; Cassee, F.R.; Boon, N.A.; Macnee, W.; et al. Do inhaled carbon nanoparticles translocate directly into the circulation in humans? Am. J. Respir. Crit. Care Med. 2006, 173, 426-431. [CrossRef] [PubMed] 
22. Brook, R.D.; Bard, R.L.; Morishita, M.; Dvonch, J.T.; Wang, L.; Yang, H.Y.; Spino, C.; Mukherjee, B.; Kaplan, M.J.; Yalavarthi, S.; et al. Hemodynamic, autonomic, and vascular effects of exposure to coarse particulate matter air pollution from a rural location. Environ. Health Perspect. 2014, 122, 624-630. [CrossRef] [PubMed]

23. Al-Kindi, S.G.; Brook, R.D.; Biswal, S.; Rajagopalan, S. Environmental determinants of cardiovascular disease: Lessons learned from air pollution. Nat. Rev. Cardiol. 2020. [CrossRef] [PubMed]

24. Delfino, R.J.; Staimer, N.; Tjoa, T.; Arhami, M.; Polidori, A.; Gillen, D.L.; Kleinman, M.T.; Schauer, J.J.; Sioutas, C. Association of biomarkers of systemic inflammation with organic components and source tracers in quasi-ultrafine particles. Environ. Health Perspect. 2010, 118, 756-762. [CrossRef] [PubMed]

25. Chambers, J.C.; Fusi, L.; Malik, I.S.; Haskard, D.O.; De Swiet, M.; Kooner, J.S. Association of maternal endothelial dysfunction with preeclampsia. JAMA 2001, 285, 1607-1612.

26. Kilinc, E.; Schulz, H.; Kuiper, G.J.; Spronk, H.M.; Ten Cate, H.; Upadhyay, S.; Ganguly, K.; Stoeger, T.; Semmler-Bhenke, M.; Takenaka, S.; et al. The procoagulant effects of fine particulate matter in vivo. Part. Fibre Toxicol. 2011, 8, 1-3. [CrossRef]

27. Loft, S.; Hogh Danielsen, P.; Mikkelsen, L.; Risom, L.; Forchhammer, L.; Moller, P. Biomarkers of oxidative damage to DNA and repair. Biochem. Soc. Trans. 2008, 36, 1071-1076. [CrossRef]

28. Moller, P.; Loft, S. Oxidative damage to DNA and lipids as biomarkers of exposure to air pollution. Environ. Health Perspect. 2010, 118, 1126-1136. [CrossRef]

29. Aplin, J.D.; Myers, J.E.; Timms, K.; Westwood, M. Tracking placental development in health and disease. Nat. Rev. Endocrinol. 2020. [CrossRef]

30. Bollati, V.; Iodice, S.; Favero, C.; Angelici, L.; Albetti, B.; Cacace, R.; Cantone, L.; Carugno, M.; Cavalleri, T.; De Giorgio, B.; et al. Susceptibility to particle health effects, miRNA and exosomes: Rationale and study protocol of the SPHERE study. BMC Public Health 2014, 14, 1137. [CrossRef]

31. Bollati, V.; Angelici, L.; Rizzo, G.; Pergoli, L.; Rota, F.; Hoxha, M.; Nordio, F.; Bonzini, M.; Tarantini, L.; Cantone, L.; et al. Microvesicle-associated microRNA expression is altered upon particulate matter exposure in healthy workers and in A549 cells. J. Appl. Toxicol. JAT 2015, 35, 59-67. [CrossRef] [PubMed]

32. Pergoli, L.; Cantone, L.; Favero, C.; Angelici, L.; Iodice, S.; Pinatel, E.; Hoxha, M.; Dioni, L.; Letizia, M.; Albetti, B.; et al. Extracellular vesicle-packaged miRNA release after short-term exposure to particulate matter is associated with increased coagulation. Part. Fibre Toxicol. 2017, 14, 32. [CrossRef] [PubMed]

33. van Niel, G.; DAngelo, G.; Raposo, G. Shedding light on the cell biology of extracellular vesicles. Nat. Rev. Mol. Cell Biol. 2018, 19, 213-228. [CrossRef] [PubMed]

34. Raposo, G.; Stahl, P.D. Extracellular vesicles: A new communication paradigm? Nat. Rev. Mol. Cell Biol. 2019, 20, 509-510. [CrossRef] [PubMed]

35. Alkoussa, S.; Hulo, S.; Courcot, D.; Billet, S.; Martin, P.J. Extracellular vesicles as actors in the air pollution related cardiopulmonary diseases. Crit. Rev. Toxicol. 2020, 1-22. [CrossRef]

36. Wahlund, C.J.E.; Eklund, A.; Grunewald, J.; Gabrielsson, S. Pulmonary Extracellular Vesicles as Mediators of Local and Systemic Inflammation. Front. Cell Dev. Biol. 2017, 5, 39. [CrossRef]

37. Schuster, J.; Cheng, S.B.; Padbury, J.; Sharma, S. Placental Extracellular Vesicles and Preeclampsia. Am. J. Reprod. Immunol. 2020, e13297. [CrossRef]

38. Zhang, J.; Li, H.; Fan, B.; Xu, W.; Zhang, X. Extracellular vesicles in normal pregnancy and pregnancy-related diseases. J. Cell. Mol. Med. 2020, 24, 4377-4388. [CrossRef]

39. Nair, S.; Salomon, C. Extracellular vesicles and their immunomodulatory functions in pregnancy. Semin. Immunopathol. 2018, 40, 425-437. [CrossRef]

40. Murthi, P.; Pinar, A.A.; Dimitriadis, E.; Samuel, C.S. Inflammasomes-A Molecular Link for Altered Immunoregulation and Inflammation Mediated Vascular Dysfunction in Preeclampsia. Int. J. Mol. Sci. 2020, 21, 1406. [CrossRef]

41. Tannetta, D.; Masliukaite, I.; Vatish, M.; Redman, C.; Sargent, I. Update of syncytiotrophoblast derived extracellular vesicles in normal pregnancy and preeclampsia. J. Reprod. Immunol. 2017, 119, 98-106. [CrossRef] [PubMed]

42. Chen, X.; Scholl, T.O. Maternal biomarkers of endothelial dysfunction and preterm delivery. PLoS ONE 2014, 9, e85716. [CrossRef] [PubMed]

43. MiRbase. Available online: http://www.mirbase.org/ (accessed on 1 September 2009). 
44. Thermo Fisher Scientific, Applied Biosystems ${ }^{\mathrm{TM}}$. Available online: https://www.thermofisher.com/order/ catalog/product/4470187\#/4470187 (accessed on 30 November 2020).

45. Silibello, C.; Calori, G.; Brusasca, G.; Giudici, A.; Angelino, E.; Fossati, G.; Peroni, E.; Buganza, E. Modelling of $\mathrm{PM}_{10}$ concentrations over Milano urban area using two aerosol modules. Environ. Model. Softw. 2008, 23, 333-343. [CrossRef]

46. ARIANET. Available online: http://doc.aria-net.it/QualeAria/wiki/QualeAria (accessed on 1 October 2020).

47. ARPA. Available online: https://www.arpalombardia.it/Pages/Aria/Modellistica/I-sistemi-modellistici-inARPA.aspx (accessed on 1 October 2020).

48. Baccini, M.; Grisotto, L.; Catelan, D.; Consonni, D.; Bertazzi, P.A.; Biggeri, A. Commuting-adjusted short-term health impact assessment of airborne fine particles with uncertainty quantification via Monte Carlo simulation. Environ. Health Perspect. 2015, 123, 27-33. [CrossRef] [PubMed]

49. Cecconi, L.; Grisotto, L.; Catelan, D.; Lagazio, C.; Berrocal, V.; Biggeri, A. Preferential sampling and Bayesian geostatistics: Statistical modeling and examples. Stat. Methods Med. Res. 2016, 25, 1224-1243. [CrossRef]

50. Grisotto, L.; Consonni, D.; Cecconi, L.; Catelan, D.; Lagazio, C.; Bertazzi, P.A.; Baccini, M.; Biggeri, A. Geostatistical Integration and Uncertainty in Pollutant Concentration Surface under Preferential Sampling. Geospat. Health 2016, 11, 56-61. [CrossRef]

51. Borghi, F.; Spinazze, A.; Campagnolo, D.; Rovelli, S.; Cattaneo, A.; Cavallo, D.M. Precision and Accuracy of a Direct-Reading Miniaturized Monitor in PM2.5 Exposure Assessment. Sensor 2018, 18, 3089. [CrossRef]

52. Bolin, J.H. Introduction to Mediation, Moderation, and Conditional Process Analysis: A Regression-Based Approach. J. Educ. Meas. 2014, 51, 335-337. [CrossRef]

53. Miller, M.R.; Newby, D.E. Air pollution and cardiovascular disease: Car sick. Cardiovasc. Res. 2020, 116, 279-294. [CrossRef]

54. Leikauf, G.D.; Kim, S.H.; Jang, A.S. Mechanisms of ultrafine particle-induced respiratory health effects. Exp. Mol. Med. 2020, 52, 329-337. [CrossRef]

55. Zhang, Y.; Salam, M.T.; Berhane, K.; Eckel, S.P.; Rappaport, E.B.; Linn, W.S.; Habre, R.; Bastain, T.M.; Gilliland, F.D. Genetic and epigenetic susceptibility of airway inflammation to $\mathrm{PM}_{2.5}$ in school children: New insights from quantile regression. Environ. Health A Glob. Access Sci. Source 2017, 16, 88. [CrossRef] [PubMed]

56. Plusquin, M.; Chadeau-Hyam, M.; Ghantous, A.; Alfano, R.; Bustamante, M.; Chatzi, L.; Cuenin, C.; Gulliver, J.; Herceg, Z.; Kogevinas, M.; et al. DNA Methylome Marks of Exposure to Particulate Matter at Three Time Points in Early Life. Environ. Sci. Technol. 2018, 52, 5427-5437. [CrossRef] [PubMed]

57. Stieb, D.M.; Chen, L.; Hystad, P.; Beckerman, B.S.; Jerrett, M.; Tjepkema, M.; Crouse, D.L.; Omariba, D.W.; Peters, P.A.; van Donkelaar, A.; et al. A national study of the association between traffic-related air pollution and adverse pregnancy outcomes in Canada, 1999-2008. Environ. Res. 2016, 148, 513-526. [CrossRef] [PubMed]

58. Hannam, K.; McNamee, R.; Baker, P.; Sibley, C.; Agius, R. Air pollution exposure and adverse pregnancy outcomes in a large UK birth cohort: Use of a novel spatio-temporal modelling technique. Scand. J. Work Environ. Health 2014, 40, 518-530. [CrossRef]

59. Class, Q.A.; Lichtenstein, P.; Langstrom, N.; D'Onofrio, B.M. Timing of prenatal maternal exposure to severe life events and adverse pregnancy outcomes: A population study of 2.6 million pregnancies. Psychosom. Med. 2011, 73, 234-241. [CrossRef]

60. Zhu, X.; Liu, Y.; Chen, Y.; Yao, C.; Che, Z.; Cao, J. Maternal exposure to fine particulate matter $\left(\mathrm{PM}_{2.5}\right)$ and pregnancy outcomes: A meta-analysis. Environ. Sci. Pollut. Res. Int. 2015, 22, 3383-3396. [CrossRef]

Publisher's Note: MDPI stays neutral with regard to jurisdictional claims in published maps and institutional affiliations. 